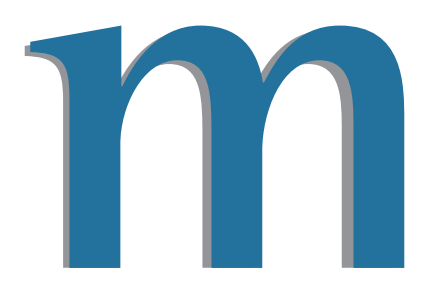

\title{
Variações excêntricas do corriqueiro: The Vegetable, Scandalabra e a escrita dramática como espaço experimental ${ }^{1}$
}

\author{
Marcela Lanius \\ Pontifícia Universidade Católica do Rio de Janeiro, Brasil \\ https://orcid.org/0000-0001-7390-0876 \\ Marcia A. P. Martins \\ Pontifícia Universidade Católica do Rio de Janeiro, Brasil \\ https://orcid.org/0000-0002-8663-1748
}

\begin{abstract}
RESUMO
The Vegetable, or From President to Postman e Scandalabra: A Farce Fantasy in a Prologue and Three Acts ainda hoje habitam o cânone dos Fitzgerald como obras de qualidade duvidosa devido ao fracasso de suas primeiras encenações - opinião esta que reflete a tendência de muitos pesquisadores em analisarem as duas peças de acordo com a tradição do teatro realista. Essa visão, no entanto, ignora por completo as expectativas do público da época, as tendências em voga no teatro que era produzido e encenado e, talvez ainda mais importante, o movimento de escrita modernista que mesclava convenções dramáticas e escrita em prosa para formular peças de natureza híbrida, os closet dramas. Este estudo analisa os dois textos dramáticos de acordo com a proposição do closet drama modernista para avaliar as rubricas criadas pelos autores enquanto um espaço de experimentação da escrita em prosa, buscando para isso paralelos com outras obras dramáticas que, escritas entre os anos 1920 e 1930, também flexibilizaram o espaço das rubricas.
\end{abstract}

PALAVRAS-CHAVE: The Vegetable; Scandalabra; Rubricas de teatro; Prosa modernista.

\section{'Bizarre variations on the normal': The Vegetable, Scandalabra and dramatic writing as experimental space}

\section{ABSTRACT}

The Vegetable, or From President to Postman and Scandalabra: A Farce Fantasy in a Prologue and Three Acts still inhabit the Fitzgerald canon as works of dubious quality due to the total disaster of their first productionsan opinion that reflects many a researcher's tendency to analyze the two plays as pertaining to the tradition of dramatic realism. This view also ignores the expectations of the public at the time, the prevalent theatrical trends, and-perhaps more importantly-Literary Modernism, which mixed dramatic conventions and prose to create hybrid pieces called closet dramas. This paper analyzes the two aforementioned plays through the Modernist closet drama perspective. It aims to recognize the authors' stage directions as a space for experimenting with prose, seeking parallels with plays that were written during the same time period and that also tried to subvert the use of stage directions.

KEYWORDS: The Vegetable; Scandalabra; Stage directions; Modernist prose.

\footnotetext{
Este estudo contou com o apoio da bolsa de pesquisa FAPERJ Bolsa nota 10.
}

Ao citar este artigo, referenciar como: LANIUS, Marcela; MARTINS, Marcia A. P. Variações excêntricas do corriqueiro: The Vegetable, Scandalabra e a escrita dramática como espaço experimental. Matraga, v. 27, n. 51, p. 614-626, set./dez. 2020.
DOI: $10.12957 /$ matraga.2020.49640 Recebido em: 29/03/2020 Aceito em: 10/06/2020 


\section{Entre máscaras e manchetes}

Alçados ao patamar de novas celebridades num momento histórico em que as manchetes de jornal controlavam narrativas individuais e orientavam a opinião pública, F. Scott e Zelda Fitzgerald ocuparam, desde muito cedo, uma posição de destaque dentro do imaginário literário norte-americano - confeccionando identidades extravagantes e exageradas de "protagonistas num melodrama, preferindo sempre o papel do observado ao do observador"2 (CHURCHWELL, 2015 , p. 279). Mas se, por um lado, é consenso entre biógrafos e pesquisadores conferir uma qualidade performática e teatral às peripécias protagonizadas pelo casal nos primeiros anos da década de 1920, por outro é curioso que os dois únicos registros dramáticos que sobrevivem dos Fitzgerald, eles mesmos tão atrelados à ideia da performatividade como uma forma de negociação de identidades públicas, recebam ainda hoje escassa atenção crítica.

Para além das análises propostas por pesquisadores como Wixson (2002, 2006), Brown (2017) e Churchwell $(2015,2018)$, pouco se discutiu sobre The Vegetable, or From President to Postman e Scandalabra: A Farce Fantasy in a Prologue and Three Acts. Consideradas, desde suas primeiras encenações, como textos de baixa qualidade técnica que simplesmente não funcionam no palco, as duas peças ainda hoje são lidas de acordo com a tradição do teatro realista; uma tradição dramática que, afinal, é insuficiente não só como chave de leitura para os dois textos, mas sobretudo como modelo de encenação, uma vez que o traço mais singular de The Vegetable e Scandalabra é o fato de que ambos situam, nas rubricas, o núcleo narrativo para a ação dramática - confeccionando, assim, personagens-narradoras situadas dentro de um espaço que é tradicionalmente invisível e menor, considerado meramente técnico.

Este artigo, então, propõe uma análise de The Vegetable e Scandalabra pelo viés do closet drama modernista - que adotou recursos e dispositivos ditos "antiteatrais" (PUCHNER, 2002, p. 2) para desafiar as convenções do teatro realista -não só para iluminar o contexto de recepção dessas peças, explicitando as diferentes nuances e convenções dramáticas que começavam a ganhar espaço no início do século XX, mas sobretudo para efetuar uma leitura mais detida das rubricas dessas duas obras enquanto espaço de experimentação da prosa modernista. Se, como afirma Luiz Fernando Ramos, a rubrica assumiu "posição de peça-chave da literatura dramática moderna" (1999, p. 37), faz-se necessário entender como os Fitzgerald utilizaram, cada um a seu modo, esse espaço em suas escritas dramáticas - para que possamos, então, reavaliar os dois textos e suas possibilidades de encenação. A análise aproxima, ainda, The Vegetable e Scandalabra dos closet dramas escritos por Marita Bonner nas décadas de 1920 e 1930, e da montagem realizada em 1934 de Four Saints in Three Acts, de Gertrude Stein, para oferecer novas possibilidades de encenação para as duas peças. Em uma análise diacrônica das publicações, abordaremos primeiro The Vegetable, para então discutir Scandalabra.

\footnotetext{
2 A tradução desta citação, assim como as demais nas quais não houver indicação de tradutor, são de nossa autoria. Destaco que as traduções de Scandalabra aqui utilizadas fazem parte da minha tese de doutorado, atualmente em desenvolvimento, que apresenta uma tradução comentada do texto. No original: "being protagonists in a melodrama, still preferring the role of the observed to the observer".
} 


\section{Farsa e fantasia na Era do Jazz: The Vegetable}

Em 1923, Scott Fitzgerald recorreu ao teatro, que havia sido um dos seus primeiros amores, para reinventar a curta carreira literária de três anos: em novembro daquele ano, sua peça The Vegetable, or From President to Postman era encenada pela primeira vez num teatro de Atlantic City. Caracterizada por Churchwell como uma sátira do governo Harding (2018, p. 102), a narrativa do escrivão transformado em presidente dos Estados Unidos (transmutado, por fim, em carteiro) foi efusivamente elogiada por Edmund Wilson, que a descreveu como "uma das melhores coisas que [Fitzgerald] já escreveu”3 (SCRIBNER III, 1976, p. viii), e por Maxwell Perkins como um texto contemporâneo, atual e "inerentemente engraçado e satírico"4 (idem, p. xii).

Contrariamente às expectativas de sucesso, no entanto, a narrativa fantástica que envolvia, no auge da Proibição, uma personagem contrabandista e a compra de álcool ilegal, e cuja personagem principal era um homem que tentava escapar da obsessão norte-americana por dinheiro e volubilidade (BROWN, 2017, p. 159), não foi bem-recebida pelo público e pela crítica. Um dos motivos para o fracasso foi o fato de que The Vegetable apresentava um descompasso desastroso entre seu enredo e o tipo de tradição dramática que então surgia nos Estados Unidos; uma tradição que começava a abandonar narrativas que pudessem ser facilmente digeridas por todo o território nacional, deixando para trás os grandes atos burlescos e fantásticos, dando lugar a um estilo de comédia mais sofisticado e palatável para a nova sociedade que agora ocupava os grandes centros urbanos. The Vegetable, uma sátira do sonho americano de sucesso (CHURCHWELL, 2018, p. 102), não apresentava a sofisticação então desejada pelo público e pela crítica até porque "dependia fortemente de enredos secundários, números burlescos e também de uma sequência fantástica sem muita graça" (BROWN, 2017, p. 159)5.

Dentre as escassas opiniões críticas sobre Vegetable, no entanto, uma se destaca: a afirmação de Charles Scribner feita na década de 1970 de que a peça fora "escrita por um romancista, e não por um dramaturgo, onde as longas rubricas por vezes oferecem os momentos mais interessantes"6 (1976, p. xvii) da experiência de leitura. As rubricas, tradicionalmente escassas no teatro realista e materializadas nas ações e movimentos dos atores ou mesmo na construção cenográfica da peça, estão separadas do chamado texto primário - que, por sua vez, identifica tudo o que é verbalizado ao longo de uma encenação; e é justamente por serem escassas que as rubricas costumam ser consideradas complementos técnicos e acessórios, imperceptíveis ao público no momento da performance (PUCHNER, 2002, p. 26). Nesse sentido, ainda que seja possível ler o comentário de Scribner como uma avaliação estética do texto ou mesmo uma forma de justificar o fracasso da peça nos palcos, a afirmação é particularmente relevante para este estudo, pois situa Vegetable em condição semelhante àquela dos chamados closet dramas, e sobretudo dos closet dramas modernistas.

\footnotetext{
3 "one of the best things you ever wrote"

4 "inherently funny and satirical"

5 "relying, as it did, on constant sideshows, burlesques, and an awkwardly unfunny fantasy sequence."

6 "remained a novelist's, not a dramatist's, play, in which the lengthy stage directions often provide the most interesting moments".
} 
Tradicionalmente entendidos como textos dramáticos - ou que apresentam a forma dramática - escritos para serem lidos, e não encenados, os closet dramas constituem uma categoria de natureza instável, pois podem ser classificados ora como literatura, ora como teatro (PUCHNER, 2002, p. 13). É dentro dessa forma híbrida, que conserva qualidades literárias e ainda assim segue o formato e as convenções dramáticas, que o movimento modernista operará uma nova expansão dos recursos antiteatrais, transformando as rubricas em um "espaço privilegiado para a inovação formal": "não mais informações técnicas, [...] as rubricas transformam-se em espaços para descrições elaboradas de personagens, de cenário e de movimentos em cena"7 (PUCHNER, 2002, p. 21). É nesse espaço que Zelda cultivará uma voz narrativa própria, e Fitzgerald, uma possível "voz autoral". Este último conceito, utilizado por Burroughs em sua análise da performatividade de gênero em The Beautiful and Damned (2002), parece apto para pensarmos as construções cômicas e satíricas que habitam as rubricas de Vegetable; rubricas estas que transbordam da ficção produzida pelo escritor entre os anos de 1920 e 1923.

Em This Side of Paradise, publicado em 1920, o leitor é introduzido a Rosalind Connage por meio de duas cenas que transformam momentaneamente a prosa narrativa em texto dramático. O capítulo seguinte, "Kismet", retoma a convenção narrativa do livro, e é só algumas páginas mais tarde, em "Five Weeks Later", que o narrador sai de cena para dar lugar mais uma vez à convenção dramática, que performa para o leitor o fim do breve e tempestuoso romance de Amory e Rosalind. Fitzgerald realizaria exercício semelhante em dois contos publicados originalmente na revista The Smart Set e coletados em Tales of The Jazz Age em 1922: "Porcelain and Pink" e "Mr. Icky: The Quintessence of Quaintness in One Act". Em "Porcelain and Pink", a rubrica inicial carrega a não-anunciada presença de um narrador dramático - que, por sua vez, interrompe de maneira abrupta a descrição do cômodo para nos informar: "O friso decorativo não faz parte do enredo mas, honestamente, sou fascinado por ele. Eu poderia continuar a descrição por horas a fio, mas um dos dois objetos do cômodo me chama a atenção - uma banheira de porcelana azul” (FITZGERALD, 2012a, p. 149) ${ }^{8}$. Em "Mr. Icky", a condição do conto enquanto texto dramático é explicitada logo no título e também nas rubricas, algumas construídas como notas para uma imaginária produção: “É possível incluir diversas músicas nesta cena, colocar DIVINE para fazer alguns truques de cartas ou mesmo contratar um número de malabarismo"9 (idem, p. 341).

Em The Beautiful and Damned, publicado também em 1922, Fitzgerald tensionará mais uma vez os limites entre prosa e escrita dramática, cultivando a voz autoral que conduzirá, mais tarde, a ação de The Vegetable. Se em This Side of Paradise as convenções dramáticas do texto teatral haviam sido empregadas como recurso estilístico, e em "Porcelain and Pink" e "Mr. Icky" a forma literária do conto fora utilizada na construção de pequenos closet dramas, em The Beautiful and Damned Fitzgerald transformará o próprio narrador do romance em voz autoral que

\footnotetext{
7 "privileged place for formal innovation"; "no longer the technical . . . stage directions were now devoted to elaborate descriptions of character, setting, and movement"

8 "The frieze is not in the plot, but frankly it fascinates me. I could continue indefinitely, but I am distracted by one of the two objects in the room - a blue porcelain bath-tub."

9 "Several songs can be introduced here or some card tricks by DIVINE or a tumbling act"
} 
conduz os trechos da ação dramática - usando, para isso, as rubricas das quatro cenas teatrais espalhadas pelo livro.

No texto teatral de The Vegetable, Fitzgerald mesclará os experimentos entre prosa e escrita dramática para criar uma sátira que, nas suas rubricas, não apenas controla a narrativa mas também comenta a ação que se desenrola nos palcos e as próprias posturas das demais personagens. Vemos, por exemplo, que no primeiro ato a descrição burlesca da casa de Jerry Frost é salpicada de comentários como "Contra a minha vontade, preciso compartilhar com vocês alguns detalhes sórdidos sobre o cômodo"10 (FITZGERALD, 2012b, p. 9) - detalhes estes que são, na verdade, indicações cênicas tradicionais, como a localização das portas e janelas. Quando Charlotte, a esposa de Frost, aparece em cena, ouvimos da rubrica: "Ela não tem uma voz muito boa, não é?"11 (idem, p. 10) - e logo mais o seguinte complemento: "Honestamente, não gosto dela, mas também ela não pode evitar de ser quem é"12 (ibidem, p. 15); na rubrica que introduz Mr. Snooks, somos confrontados com a artificialidade do espetáculo teatral e com a natureza mutável da rubrica, que mais uma vez se coloca enquanto sujeito criador: "Eu gostaria de poder apresentar a vocês o modelo original para o Sr. Snooks"13 (ibidem, p. 32). Em última análise, o que a voz autoral das rubricas de The Vegetable faz é trazer para o texto dramático uma escrita que não consegue se concretizar em cena, ou que não poderia ser concretizada em cena de acordo com o modelo e as convenções do teatro realista.

\section{Farsa e fantasia durante a Grande Depressão: Scandalabra}

Se a peça convoluta e inicialmente fracassada de Scott Fitzgerald pode ser lida como um closet drama modernista e como um texto "emblemático da paradoxal Era do Jazz, repleto de corrupção, experimentações, vitalidade e descentralização" (WIXSON, 2006, p. 59) ) $^{14}$, então também podemos ampliar esse exercício de contextualização histórica e crítica para Scandalabra - e veremos que também essa peça foi lida como em descompasso com os códigos e tendências do teatro realista da época.

Zelda escreveu Scandalabra entre junho de 1932 e junho de 1933 - um período de doze meses no qual viveu, além da sua liberação da clínica psiquiátrica de Phipps, a publicação e consequente recepção crítica de seu único romance concluído, Save Me the Waltz. Finalizado ainda na clínica como um esforço de continuar o exercício da escrita profissional, Save Me the Waltz ganhara, depois do colapso e consequente diagnóstico de esquizofrenia de sua autora, a dimensão de veículo para independência e autonomia artística. Mas, para além de contextualizar os meses de concepção de Scandalabra, esses acontecimentos também nos ajudam a entender a escolha de Zelda por um tema tão inesperado como a farsa durante o fragilizado início da década de 1930.

\footnotetext{
10 "Against my will, l'll have to tell you a few sordid details about the room"

11 "She hasn't got much of a voice, has she?"

12 "Frankly, I don't like her, though she can't help being what she is"

13 "I wish I could introduce you to the original from whom I have taken Mr. Snooks"

14 "emblematic of the paradox of the Jazz Age itself, replete with corruption, experimentation, vigor, and the loss of the center."
} 
Aliada aos acontecimentos e eventos acima mencionados, há também a possibilidade de que a peça tenha sido escrita como uma alternativa ao novo romance que Zelda havia começado e que possivelmente seria centrado na figura do bailarino russo Nijinsky (WAGNER-MARTIN, 2004, p. 203; BRUCCOLI, 1993, p. 406). Além disso, Scandalabra parece também ter sido a forma que Zelda encontrou de acatar as demandas feitas por Fitzgerald de que se a esposa escrevesse uma peça, esta não poderia "ser uma peça sobre psiquiatria, e não pode[ria] se passar na Riviera, e também não pode[ria] se passar na Suíça, e qualquer que fosse a ideia do enredo, precisar[ia] ser aprovada por mim"15 (MILFORD, 1970, p. 275; BRUCCOLI, 1993, p. 406-407).

É dentro desse cenário, então, que Zelda construirá uma farsa fantástica sobre os (então escassos) extremamente ricos. Absurda, hilária e verdadeiramente irônica, Scandalabra conta a história de um jovem fazendeiro que se descobre herdeiro da fortuna do tio. O impasse cômico que norteia a ação dramática da peça está na condição estipulada no testamento de que, para receber o dinheiro, o fazendeiro e a esposa devem seguir um caminho moralmente corrupto e incorreto. O herdeiro Andrew, inapto para tal destino, acaba sendo controlado e enredado pelo falso caso extraconjugal armado por sua esposa - esta, escolhida a dedo para o casamento por conta de sua carreira como vedete na chorus line. Para que conquistem o final feliz e a fortuna que este carrega consigo, o casal deve se comportar de maneira escandalosa e subverter as crenças da época, numa comédia de erros absurdos e irreparáveis.

Tal como a narrativa de Frost idealizada por Scott Fitzgerald, as confusões de Andrew e Flower Messogony se colocam marcadas por um momento e por um contexto social específico - a Nova York da década de 1920, tão emblemática como lócus de glória, extravagância e riqueza que, frente à grave depressão econômica que naquele momento assolava o país, parecia mais um disparate incômodo a ser descartado o mais rápido possível. Esse desalinho é um dos motivos pelos quais a peça não funcionou em sua primeira montagem; afinal, o modelo da farsa teatral já estava datado durante os anos da Depressão (WAGNER-MARTIN, 2004, p. 172), e as muitas referências culturais e sociais que Zelda utiliza ao longo da peça eram consideradas ultrapassadas - o que também comprova o verdadeiro desalinho entre a autora e o mundo que habitava. Empresas e lojas já falidas, viagens para luxuosas praias francesas e personagens da cultura popular que estiveram no seu auge durante a década de 1920 e agora eram apenas figuras do passado, tal como a flapper e a Gibson Girl, dão vida ao enredo de Scandalabra e conferem um toque marcadamente ácido para o público da época, então enfrentando uma realidade completamente oposta e acostumado a uma tradição dramática diferente. No período da Grande Depressão, as peças teatrais que haviam reinado durante o pós-guerra e especialmente durante a Era do Jazz, que tinham como traço principal a veia cômica ou satírica altamente sofisticada, agora eram substituídas por um teatro que tinha no engajamento político o fio condutor da ação dramática (WIXSON, 2002, p. 44).

Contudo, o enredo fantástico escondido nessa peça de nome exótico parece carregar muito mais do que um círculo social em decadência; e, de fato, há em Scandalabra uma forte intertex-

15 "it cannot be a play about psychiatry, and it cannot be a play laid on the Riviera, and it cannot be a play laid in Switzerland, and whatever the idea is, it will have to be submitted to me" 
tualidade com The Beautiful and Damned (MILFORD, 1970, p. 278; BRUCCOLI, 1994, p.407) e também com a peça The School for Scandal, de Richard Sheridan. As semelhanças com a peça de Sheridan - em especial a negociação de escândalos sociais e a construção de relações extraconjugais como moeda de troca para favores e subornos - também foram exploradas por Wixson, que afirma:

Sem dúvida, a peça foi fortemente inspirada por Richard Sheridan, Oscar Wilde e Noel Coward; e não é de se espantar que as acrobacias linguísticas e intrigas cômicas desses três dramaturgos tenham agradado Zelda, que usa livremente muitas construções propostas por eles. (2002, p. 43) ${ }^{16}$

As semelhanças com a obra dramática de Oscar Wilde foram observadas também por Bruccoli, que identificou uma qualidade neo-wildeana (1993, p. 407) no texto; e, de fato, o uso recorrente de aforismos e a presença exagerada de trocadilhos e expressões cotidianas carrega semelhanças com as falas que compõem a ação de The Importance of Being Earnest. Talvez ainda mais interessante, no entanto, é a manipulação que as personagens wildeanas fazem da realidade - algo que se coloca central também em Scandalabra. Na comédia de Wilde, Cecily faz do diário pessoal canal de registro e consequente comprovação de sua realidade inventada, da mesma forma que, em Scandalabra, Connie Consequential recorre aos tabloides como fonte de verdade absoluta, capaz de sobrepujar mesmo as falas e alegações de seu marido. Enfim satisfeita com a identidade do cônjuge tal qual retratada nos jornais, Connie é categórica ao defender suas crenças, pois tudo aquilo "saiu até no jornal"17 (FITZGERALD, 1991, p. 234).

Comentário e sátira social, a farsa criada por Zelda - que, à primeira vista, pode ser invalidada como um texto irrelevante ou tolo para a época - trata de questões especificamente contemporâneas, como "a debilidade moral, a hipocrisia social e a centelha efêmera da revolta da juventude" (Wixson, 2002, p. 44) ${ }^{18}$; e não estaria, portanto, tão distante assim das temáticas e dos códigos aceitos na nova tradição dramática dos anos 1930. Há, no entanto, outras desarmonias entre Scandalabra e seu contexto social de recepção - e o principal deles está no fato de que a peça foi fortemente influenciada por um referencial obsoleto e, naquele momento, pouco popular dentro do teatro norte-americano: a tradição dramática britânica do período da Restauração (WIXSON, 2002, p. 54). De fato, Zelda se apropria de convenções como

os nomes comicamente alegóricos de "Andrew Messogony" e "Anaconda Consequential" e o uso frequente de disparates ${ }^{19}$, como as instruções deixadas por Uncle Andrew para que seu "sobrinho tenha todas as desvantagens desse mundo". No entanto, Zelda [...] dramatiza uma cultura na qual a negociação de escândalos sociais se transforma não só num instrumento para o entretenimento público, mas também em um caminho para o sucesso dentro daquela sociedade. As concepções

\footnotetext{
16 "Scandalabra owes its greatest dramaturgical debt to Richard Sheridan, Oscar Wilde, and Noel Coward. Unsurprisingly, their linguistic acrobatics and farcical intrigues seem to have appealed greatly to Zelda, and she borrows liberally from all three."

17 "it says so in the papers"

18 "issues of moral infirmity, social hypocrisy, and the ephemeral spark of youthful rebellion"

19 tradução adotada para malapropism ("the usually unintentionally humorous misuse or distortion of a word or phrase; especially : the use of a word sounding somewhat like the one intended but ludicrously wrong in the context", Merriam-Webster online), segundo Martins, 2004.
} 
de caráter e reputação são subvertidas, e a identidade pública aceitável de uma pessoa é uma inerentemente imoral - e a má fama que vem com esse comportamento, algo altamente desejável. (WIXSON, 2002, p. 46) $)^{20}$

A sátira social que constrói o enredo de Scandalabra, portanto, faz uso de uma tradição essencialmente não-americana para discutir questões essencialmente norte-americanas como o culto às celebridades, as dinâmicas sociais de classe e os escândalos dos muito ricos. Ao criar uma situação fantástica a partir de um caso extraconjugal que não existe a não ser em teoria, fabricado apenas para agradar as expectativas de uma sociedade imoral e o apetite dos jornais sensacionalistas, Zelda consegue abordar temas ainda hoje atuais, como "identidade, celebridade, gênero e tabloides" (WIXSON, 2002, p. 34). ${ }^{21}$

\section{Entre rubrica e narração: a voz narrativa de Scandalabra}

Tal como The Vegetable, Scandalabra também não desfrutou do sucesso sonhado por sua autora. Após uma semana desastrosa nos palcos, e críticas que a descreviam como uma "fantasia amalucada" 22 , a montagem foi encerrada, e Zelda, que desconhecia as "demandas e convenções da escrita dramática - e [estava] abatida com a recepção do público e da crítica" (WIXSON, 2002, p. 35) ${ }^{23}$, abandonou o manuscrito. Scandalabra entraria para o cânone dos Fitzgerald como o último grande esforço de Zelda no campo da escrita e, principalmente, como curiosidade literária de baixa qualidade.

No entanto, uma análise detida desse texto dramático, por vezes confuso e não linear, indica que é nas rubricas que seu potencial como obra dramática se constrói, pois é ali, num espaço secundário, invisível e menor, que Zelda construirá uma voz autoral singular e altamente poderosa - elaborando, dessa forma, uma possível representação daquilo que Ramos identificaria como "enunciador didascálico": um sujeito oculto que, antes subordinado aos diálogos, passa a ocupar um espaço que vai além da indicação cênica tradicional, "atuando não só como guia do leitor, mas como constituinte imprescindível do espaço da ficção” (RAMOS, 1999, p. 34). Um exemplo desse enunciador didascálico se dá na descrição do vestido da personagem Connie Consequential quando esta entra em cena: “Ainda bem que há um avental separando o suco de laranja e o vestido, pois assim não há risco de manchas e ela pode usá-lo novamente amanhã à noite" (FITZGERALD, 1991, p. 231). ${ }^{24}$ Nesse sentido, então, Scandalabra compartilha do tom

\footnotetext{
20 "comically allegorical character names such as "Andrew Messogony" and "Anaconda Consequential" as well as frequent semi-malapropisms like Uncle Andrew's directive to his butler to "see that [his] nephew gets all the disadvantages" (204). Yet, Zelda . . . dramatiz[es] a culture in which scandal mongering becomes not only the way in which the masses are entertained but the way in which social success is achieved. Notions of character and reputation have been perverted so that the expected public identity is inherently immoral, and notoriety for such behavior is sought after actively."

21 "touching on issues of identity, celebrity, gender, and the media"

${ }_{22}$ The Baltimore Sun, 27 de junho de 1933. Pode ser acessado via https://baltimoresun.newspapers.com/. No original: "a fantasy gone haywire"

23 "demands and conventions of writing in this form and disheartened by its reception"

24 "luckily, there's an apron between the dress and the orange juice, so it won't be ruined and Connie can wear it again tomorrow night"
} 
característico das peças de toda uma tradição do teatro moderno, que entende as rubricas e as indicações cênicas como um lugar da maior relevância e também como um espaço de expressão autoral, no qual a figura do dramaturgo se deixa transparecer num diálogo honesto e direto com o público:

Diferentemente da maioria das indicações cênicas que geralmente pontuam entradas ou saídas de personagens ou então apenas identificam ações que devem ser transmitidas de maneira visual durante uma encenação, as rubricas de Zelda exibem uma voz narrativa distinta [...] para comentar as ações da peça. (WIXSON, 2002, p. 41) ${ }^{25}$

Dessa forma, a voz narrativa construída por Zelda funciona como uma personagem exterior ao desenrolar da peça; um elo entre o leitor-espectador e a ação que acontece no palco; uma voz narrativa onde a própria Zelda, dramaturga-personagem, se comunica:

Um dos traços mais perturbadores de Scandalabra é a presença de uma única palavra localizada na primeira frase da primeira indicação cênica; uma palavra que tem importância incontestável devido ao momento que Zelda estava vivendo, mas que raramente se faz presente nesse espaço do texto dramático. É o pequeno pronome "eu", que significa e apresenta o leitor à voz narrativa que habitará o restante das indicações cênicas. [...] Zelda declara, logo na primeira frase da peça, o "eu" que garante a sua presença ao longo do texto, [...] [e], mais tarde, usa essa mesma voz para se firmar enquanto artista. (idem, p. 41-42) ${ }^{26}$

É em Scandalabra, portanto, que Zelda recria e reclama para si o papel de personagem que lhe havia sido conferido pelo marido, tecendo não só sua própria voz narrativa, mas também personagens mulheres que simbolizam, para além da complicada dinâmica de classes da sociedade norte-americana, os danos e os perigos de uma identidade formada exclusivamente a partir de opiniões masculinizadas, na imagem de Flower; e os triunfos de uma flapper inesquecível e palhaça, incorporada por Connie. É por meio da sua farsa fantástica que Zelda não só desenvolve a linguagem que havia começado a praticar em Save Me the Waltz (WAGNER-MARTIN, 2004, p. 145), mas também mostra como é fácil perder o controle sobre essa linguagem e sobre a própria identidade; e é também nessa sua única peça que ela mostrará as consequências e provações enfrentadas por personagens cujas identidades são pré-construídas pela mídia e pelas convenções sociais (WIXSON, 2002, p. 48).

A forma como Zelda manipula o espaço invisível da rubrica, transformando-o em comentário, narração e prosa escrita num esforço que simultaneamente desestabiliza as fronteiras convencionais do teatro e ressalta a própria artificialidade que é condição primeira para a experiência dramática, aproxima o texto de um closet drama modernista, embora tenha sido inicial-

25 "Unlike much stage direction that merely identify entrances, exits, and basic information that can be communicated to the audience visually during performance, Zelda's possesses a distinct narrative voice, more akin to that of George Bernard Shaw, commenting upon the play in fanciful language more suited to the page than the stage." 26 "What is perhaps most disorienting about reading Scandalabra is the presence of one word located in the very first sentence of the stage directions, a word which has obvious importance to Zelda during this time but one which rarely strays into stage directions. It is simply the pronoun "I" which signifies and introduces the reader to the larger presence of a narrative voice in the stage description throughout the play. . . . She asserts in the first sentence an "I" which assures Zelda's presence in the text . . . Later, she uses this voice to affirm herself as an artist." 
mente formulado para uma encenação concreta nos palcos. O resultado final, portanto, é um texto híbrido, que não foge totalmente das normas do teatro (PUCHNER, 2002, p. 18) e mesmo assim conserva fortes paralelos com textos dramáticos considerados altamente experimentais.

\section{0 closet drama modernista como chave de leitura}

Se a voz narrativa de Scandalabra é um de seus recursos mais singulares e idiossincráticos, pois representa uma situação semelhante à descrita por Ramos - onde "a ação deixa de estar inscrita nos diálogos e passa a ser narrada nas rubricas" (1999, p. 37) - confirma-se a proposição de Puchner de que, nos closet dramas, as rubricas são tão centrais que não podem mais "simplesmente desparecer durante o processo de montagem"27 (PUCHNER, 2002, p. 27). Nesse sentido, pode ser produtivo aproximar o texto de Scandalabra de Four Saints in Three Acts, de Gertrude Stein - ópera concluída pela autora em 1927 e encenada pela primeira vez em 1934. Demarcada por Puchner como um tipo particularmente estranho de closet drama (2002, p. 101), Four Saints não possui dramatis personae, divisão de atos ou um enredo concreto - e também não há como distinguir entre as falas e as indicações cênicas (idem, p. 101). Para além disso, Stein também atua como uma personagem dentro da peça (BOWERS, 2005, p. 161), construindo nas rubricas uma voz autoral que abarca instruções cênicas, comentários e narração - misturando, portanto, os limites entre real e ficção.

Do mesmo modo, a própria existência da voz narrativa de Scandalabra e da voz autoral de The Vegetable atenta para o fato de que essas experimentações em prosa não eram acontecimentos isolados nas primeiras décadas do século XX. The Pot Maker, The Purple Flower e Exit, an Illusion - as três peças escritas por Marita Bonner - também adotam uma forma híbrida (BURTON, 1996, p. xxxviii), posto que não só estabelecem uma voz narrativa que se assemelha à de um(a) narrador(a) (idem, p. xli), mas também cultivam um discurso que "orienta o foco do leitor-espectador, criando um texto que é parte peça teatral e parte conto"28 (idem, p. xxxviii). Bonner também demonstra, como Fitzgerald, uma preocupação maior do que Zelda e Stein em delimitar a construção dos cenários, indicando - como na rubrica inicial de The Pot Maker - a localização exata das janelas, portas e cômodos da casa que abriga a ação; no entanto, a dramaturga também constrói rubricas como esta:

Ao subir a cortina, a expectativa é grande em todos. A MÃE senta-se, tesa, na ponta da cadeira. Seu rosto e corpo dizem, "Me deixe orgulhosa! Você é meu filho! Me deixe orgulhosa!". O PAI, por sua vez, senta-se acomodado. [...] Uma boa descrição, no geral. Consegue vê-los? (BONNER, 1996, p. 108) ${ }^{29}$

\footnotetext{
27 "can no longer simply disappear in the process of staging"

28 "direct[s] the viewer-reader focus's, making the text part play and part short story"

29 "As the curtain draws back, expectation rests heavily on everyone. MOTHER is poised stiffly on the edge of her chair. Her face and her body say, 'Do me proud! You're my son! Do me proud!' FATHER on his side rests easily on his chair ... That sums them up in general, too. Can you see them?"
} 
A voz narrativa de Scandalabra, por sua vez, descreve uma de suas personagens como "um homem tão rico que acredita que só sofre de depressão quem tem problemas cardíacos"30 (FITZGERALD, 1991, p. 201); e a outra, como um jovem que vive seus dias "como quem está sempre pedindo desculpas por existir, e isso quase que apaga toda sua beleza - mas ainda há ali um traço ou outro do que ele costumava ser"31 (idem, p. 209).

É por meio da voz autoral, no caso de Fitzgerald e Stein, e da voz narrativa, no caso de Zelda e Bonner, que o texto teatral e, sobretudo, as suas rubricas se constroem como um espaço de experimentação da forma escrita e da prosa modernista - transformando não apenas a própria experiência dramática da performance, mas principalmente um espaço textual que era tradicionalmente invisível em um lugar de criação, subversão e comentário. Nesse sentido, é importante destacar o caráter de singularidade e inadequação que essas obras conservam dentro de seus momentos de produção. Para além do já mencionado descompasso de Scandalabra e The Vegetable às tendências dramáticas então vigentes, as peças de Bonner, por exemplo, foram consideradas diferentes das outras peças escritas por dramaturgos afro-americanos daquela época e nunca receberam encenações enquanto a autora estava viva (BURTON, 1996, p. xl); e Four Saints, que atingiu sucesso considerável na Broadway em 1934, precisou passar por modificações significativas para que pudesse ser devidamente montada. As modificações operadas no texto de Four Saints culminaram sobretudo na criação das personagens "commere" e "compere", responsáveis por transmitir oralmente as rubricas do texto (PUCHNER, 2002, p. 113). A materialização do texto secundário, aliás, também foi concretizada no palco:

[U]ma cortina divide o palco em duas áreas, uma para a ação primária e outra para a ação secundária, respectivamente. Enquanto o palco interno é reservado para as personagens primárias, as personagens diegéticas habitam o palco externo, e é a partir dele que comentam a ação do palco interno. (PUCHNER, 2002, p. 112) ${ }^{32}$

Os ajustes de caráter cênico operados no texto de Stein, ora classificado como literário e ora como closet drama, são importantes para uma análise de The Vegetable e Scandalabra enquanto textos dramáticos justamente porque sua concretude nos palcos nos oferece formas de pensar novas leituras críticas e possíveis caminhos cênicos para a voz autoral de Fitzgerald e a voz narradora das rubricas de Zelda. A possibilidade de concretização dessas vozes no palco, seja via voz gravada ou mesmo, como aconteceu na montagem de Four Saints, via um processo de personificação e corporificação, nos permite colocar as duas peças dos Fitzgerald como textos com potencial que ultrapassa o enquadramento de fracassos que funcionam melhor na página do que no palco - pois viabiliza, sobretudo, um reajuste na forma como lemos esses textos. Não mais obras de qualidade duvidosa, The Vegetable e Scandalabra podem ser entendidos como pertencentes a uma tradição dramática que é específica e explicitamente modernista.

\footnotetext{
30 "so rich that he thinks a depression is something caused by heart trouble"

31 "[Andrew's] apologetic approach to life has almost effaced his attractions but they're there"

32 "a curtain divides the stage into two designated areas, for the primary and secondary action, respectively. While the inner stage is preserved for the primary cast, the diegetic characters are placed on the outer stage, from which they comment on the action taking place within."
} 
Ao modificar as rubricas em exercícios de prosa e comentário, Scott Fitzgerald vai na contracorrente do que era, à época, considerado aceitável enquanto arte dramática para mostrar que, embora qualquer pessoa possa ser presidente, são poucos os que devem seguir esse caminho (CHURCHWELL, 2018, p. 102); ao recorrer à farsa para retratar uma sociedade construída na fabricação e no consumo de escândalos pela mídia e manipulações de identidades privadas para a manutenção do senso comum, Zelda Sayre Fitzgerald se vale das rubricas para reafirmar, criticar e ironizar não só as personagens em cima do palco, mas também o leitor-espectador.

\section{REFERÊNCIAS}

BONNER, Marita. The Pot Maker. In: BURTON, Jennifer (Org.). Zora Neale Hurston, Eulalie Spence, Marita Bonner, and Others: The Prize Plays and Other One-Acts Published in Periodicals. New York: G. K. Hall \& Co., 1996.

BOWERS, Jane Palatini. The Play as Lang-scape: 1920 to 1933. In: BLOOM, Harold. (Ed.). Modern American Drama. Philadelphia: Chelsea House Publishers, 2005.

BROWN, David S. Paradise Lost: A Life of F. Scott Fitzgerald. Cambridge/London: The Belknap Press of Harvard University Press, 2017.

BRUCCOLI, Matthew J. Some Sort of Epic Grandeur: The Life of F. Scott Fitzgerald. New York: Carrol \& Graf, 1993.

BURROUGHS, Catherine B. Keats's Lamian Legacy: Romance and Performance of Gender in The Beautiful and Damned. In: BRYER, Jackson; MARGOLIES, Alan; PRIGOZY, Ruth (Eds.). F. Scott Fitzgerald: New Perspectives. Athens, Georgia: The University of Georgia Press, 2000.

BURTON, Jennifer. Introduction. In: BURTON, Jennifer (Org.). Zora Neale Hurston, Eulalie Spence, Marita Bonner, and Others: The Prize Plays and Other One-Acts Published in Periodicals. New York: G. K. Hall \& Co., 1996.

CHURCHWELL, Sarah. Careless People: Murder, Mayhem, and the Invention of The Great Gatsby. United States: Penguin Books, 2015.

CHURCHWELL, Sarah. Behold, America: The Entangled History of 'America First' and 'The American Dream'. New York: Basic Books, 2018.

FITZGERALD, F. Scott. Tales of the Jazz Age. London: Collector's Library, 2012a.

FITZGERAlD, F. Scott. The Vegetable, or From President to Postman. San Bernardino: Whisky Priest, $2012 b$.

FITZGERALD, Zelda. The Collected Writings of Zelda Fitzgerald. Edited by Matthew J. Bruccoli. Alabama: The University of Alabama Press, 1991.

MARTINS, Marcia (Org.) Versões e identidades brasileiras de Shakespeare. Rio de Janeiro: Editora Lucerna, 2004.

MILFORD, Nancy. Zelda: A Biography. New York: Harper Perennial, 1970. 
PUCHNER, Martin. Stage Fright: Modernism, Anti-Theatricality, and Drama. Baltimore: The John Hopkins University Press, 2002.

RAMOS, Luiz Fernando. O parto de Godot e outras encenações imaginárias: a rubrica como poética da cena. São Paulo: Editora Hucitec, 1999.

SCRIBNER III, Charles. Introduction. In: FITZGERALD, F. Scott. The Vegetable, or From President to Postman. New York: Collier Books, 1976.

WAGNER-MARTIN, Linda. Zelda Sayre Fitzgerald: An American Woman's Life. Great Britain: Palgrave Macmillan, 2004.

WIXSON, Christopher. 'A Very Carefully Orchestrated Life': Dramatic Representations of and by Zelda Fitzgerald. American Drama, volume 11, n 1, p. 32-57, 2002.

WIXSON, Christopher. Ragged Edges: The Curious Case of F. Scott Fitzgerald's The Vegetable. American Drama, volume 15, nº 2, p. 48-60, 2006. 